nary bypass on circulating lymphocyte function. Ann Thorac Surg 1992;53:611-6.

3. Fernandez LA, MacSween JM, Langley GR. Lymphocyte responses to PHA: age-related effects. Immunology 1976;31: $583-7$.

4. Salomon NW, Page US, Bigelow JC, Krause AH, Okies JE,
Metzdorff MT. Coronary artery bypass grafting in elderly patients. J Thorac Cardiovase Surg 1991;101:209-18.

5. Bull DA, Karwande SV, Hawkins JA, Neumayer LA, Taylor $\mathrm{DO}$, Jones $\mathrm{KW}$, et al. Long-term results of cardiac transplantation in patients older than sixty years. J Thorac Cardiovasc Surg 1996;111:423-8.

\title{
AORTIC ROOT ENDOSCOPY IN VALVE-SPARING OPERATIONS
}

\author{
Tsuyoshi Itoh, MD, Satoshi Ohtsubo, MD, Kojiro Furukawa, MD, and Hiroaki Norita, MD, Saga, Japan
}

Reconstructive operations on the aortic root have been revolutionized since a valve-sparing procedure was demonstrated to be a viable alternative to the conventional method of replacement with a composite valved graft. The new procedure aims to replace diseased aortic wall while preserving the native aortic valve and anulus. In 1992, David and Feinde ${ }^{1}$ reported original results with successful valve-sparing surgery by reimplanting the aortic valve in a tubular Dacron graft (reimplantation). Sarsam and Yacoub ${ }^{2}$ proposed a different technique of restoring the normal geometry to the aortic root, using a tailored Dacron graft (remodeling). Both operations require sophisticated techniques with an accurate anatomic understanding of the diseased aortic root. Although mathematical estimation based on the normal geometry of the aortic root is informative, ${ }^{3,4}$ several adjustments to the suture line may be required to decrease persistent aortic insufficiency when considering individual anatomic differences. An intraoperative macroscopic evaluation of the repaired aorta is not always accurate, because once the root has been opened, the aortic cusps are released from perfusion pressure and the root loses its tension and strain. The natural configuration of the root is thus manipulated, and recognizing any malcoaptation or overstretching becomes difficult. A reliable measure is required to cope with the diversity in the anatomic characteristics of a diseased aorta. This article reports the result of successful aortic valve-sparing surgery performed with the use of endoscopic guidance.

To date, we have successfully performed aortic root repair in five cases in which aortic root endoscopy was introduced to observe the valves during the operations.

From the Department of Thoracic and Cardiovascular Surgery, Saga Medical School, Saga, Japan.

Received for publication Nov. 25, 1996; accepted for publication Dec. 31, 1996.

Address for reprints: Tsuyoshi Itoh, MD, Department of Thoracic and Cardiovascular Surgery, Saga Medical School, 5-1-1 Nabeshima, Saga City, Saga 849, Japan.

J Thorac Cardiovasc Surg 1997;114:141-2

Copyright (C) 1997 by Mosby-Year Book, Inc.

$0022-5223 / 97 \$ 5.00+0 \quad \mathbf{1 2 / 5 4 / 8 0 0 9 5}$
One of the patients was a 70-year-old man who was admitted for the treatment of an enlarged ascending aortic aneurysm. Preoperative findings eliminated Marfan syndrome and other degenerative connective tissue disease. A computed tomographic scan of the chest showed the maximum diameter of the aortic aneurysm to be 60 $\mathrm{mm}$, and aortography revealed severe aortic regurgitation. Transesophageal echocardiography showed the nondilated aortic anulus with massive central regurgitation. Thus the cause of the regurgitation was suspected to be dilatation of the sinotubular junction.

An operation was performed through a median sternotomy. A two-staged single venous cannula was inserted into the right atrium. The left femoral artery was cannulated as the arterial line. Cardiopulmonary bypass was initiated and the systemic temperature was reduced to $26^{\circ} \mathrm{C}$. After crossclamping of the aorta, a flexible electric laparoscope (Fujinon Video Laparoscope Systems, Fujinon, Saitama, Japan), the tip diameter of which was $10.3 \mathrm{~mm}$, was inserted into the ascending aorta. One liter of crystalloid cardioplegic solution was infused into the root, and the aortic root was then visualized with an endoscope. This

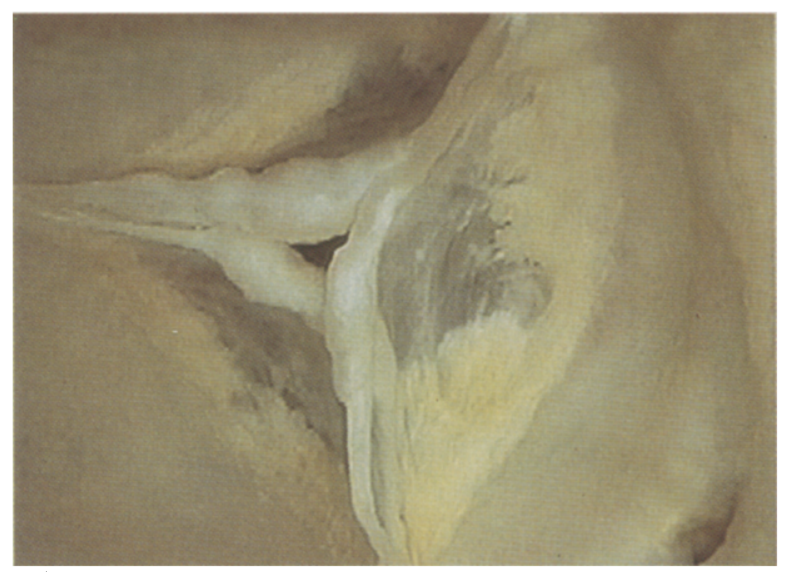

Fig. 1. Endoscopic findings before repair in the patient. Central malcoaptation was found. No organic change was found except slight thickening in the leaflet edge. 


\section{Brief communications}

The Journal of Thoracic and

Cardiovascular Surgery

July 1997

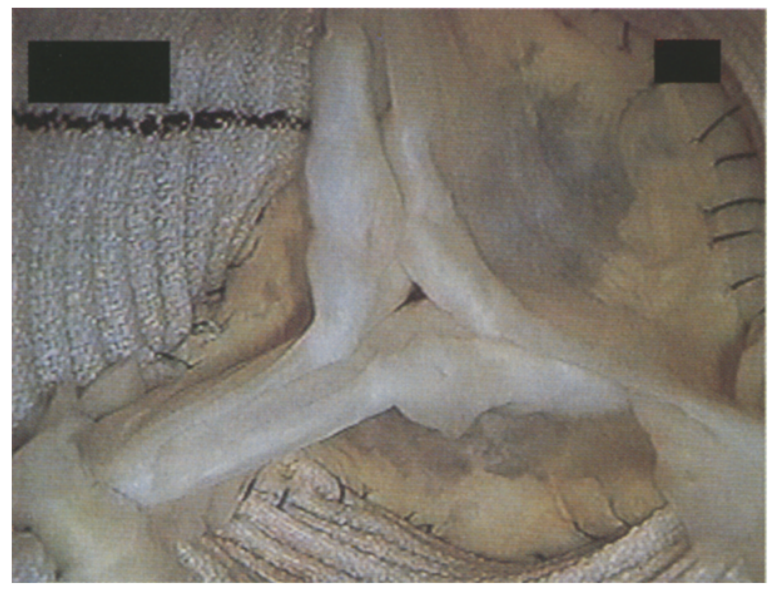

Fig. 2. Endoscopic findings after repair in the patient. Central detachment was decreased and valve coaptation was improved.

revealed that the leaflets were not coapting at a central portion, but the lack of coaptation did not produce significant prolapse. No organic change was found except for a slight thickening of the leaflet edge (Fig. 1). Remodeling of the root was selected as the operative procedure because degeneration in the anulus was unlikely in this case. The procedure used was similar to that described by Sarsam and Yacoub. ${ }^{2}$ All three sinuses were excised, with $2 \mathrm{~mm}$ of the arterial wall left above the aortic anulus and a small button of the aortic wall around the ostia of the coronary arteries. A collagen-impregnated Dacron graft was used, with a diameter similar to that of the left ventricular outlet. Then each commissure was pulled up and the height of the commissure was measured. The proximal end of the graft was then tailored to be scallopshaped, so that the top of the scallop was matched to the commissure level. The graft was then sutured to the aortic rim with continuous 4-0 polypropylene suture. Endoscopic evaluation was again performed. Additional sutures were placed to lift each commissure, and valve coaptation was improved (Fig. 2). Both coronary arteries were reimplanted and the distal graft anastomosis was completed. The aortic crossclamp time was 177 minutes and the total pump time was 256 minutes. The postoperative recovery was smooth and uneventful, and aortography demonstrated no aortic regurgitation.

With a decline in the prevalence of rheumatic valvular disease, it is increasingly apparent that aortic regurgitation may develop in patients having an ascending aortic aneurysm even though they have a normal valve. This is due to a dilatation of the sinotubular junction, distortion of the sinuses of Valsalva, annuloaortic ectasia, or a combination of these problems. In these patients, the diseased aortic root can be reconstructed while the native valve is being preserved. The remodeling procedure seems to create more physiologic geometry than the reimplantation procedure. In degenerative aortic disease, particularly with dilated aortic anulus, however, the reimplantation procedure seems preferable to the remodeling procedure, where a proximal end of a tubular vascular graft is expected to prevent further annular dilatation.

Under endoscopic guidance, we have successfully performed aortic valve-sparing operations in five cases (four reimplantations, one remodeling). In all cases, the use of crystalloid cardioplegia allowed the root to be clearly visualized. The aortic cusps were loaded by the perfusion pressure of the cardioplegic solution, which simulated the diastolic phase in the aortic root. Persistent regurgitation could thereby be recognized early and corrected before weaning from cardiopulmonary bypass, which otherwise would not be feasible with transesophageal echocardiography. Aortic root endoscopic evaluation may help to identify the suitable operative procedure and improve the long-term results of valve-sparing operations by preventing persistent valve regurgitation.

\section{REFERENCES}

1. David TE, Feindel CM. An aortic valve-sparing operation for patients with aortic incompetence and aneurysm of the ascending aorta. Ann Thorac Surg 1992;104:617-22.

2. Sarsam MA, Yacoub M. Remodeling of the aortic valve anulus. J Thorac Cardiovasc Surg 1993;105:435-8.

3. Kunzelman KS, Grande KJ, David TE, Cochran RP. Aortic root and valve relationship. J Thorac Cardiovase Surg 1994; 107:162-70.

4. Cochran RP, Kunzelman KS, Eddy AC, Hofer BO, Verrier ED. Modified conduit preparation creates a pseudosinus in an aortic valve-sparing procedure for aneurysm of the ascending aorta. J Thorac Cardiovasc Surg 1995;109:1049-58. 